\title{
Dialécticas Espaciais na Cidade Contemporânea e o poder integrador do desenho urbano
}

Luis Balula*

\begin{abstract}
$\mathrm{R}$ Lesumo: $\mathrm{O}$ presente artigo propõe uma análise das dinâmicas de urbanização emergentes das transformações estruturais do pós-fordismo. Examinam-se os aspectos formais da reorganização do espaço urbano e as contradições inerentes à sua actual produção num contexto de urbanismo "pós-modernista". Face à crescente despacialização da esfera pública, e à crescente privatização do espaço público, propõe-se a recuperação das morfologias espaciais rejeitadas pelo modernismo, enquanto contributo fundamental do planeamento físico contemporâneo para o reforço da comunicação e da coesão social.
\end{abstract}

Palavras-chave: Desenho urbano; Espaço público; Espaço pré-modernista; Espaço modernista; Urbanismo neo-tradicional.

A oposição dialéctica entre urbanismo e urbanização, tal como definida por Andrew Merrifield em Dialectical Urbanism: Social Struggles in the Capitalist City (Merrifield, 2002:115), é elucidativa das contradições inerentes à actual produção de espaço urbano. Enquanto que urbanismo se refere à cidade enquanto experiência vivida, uma experiência subjectiva de lugares com um valor de uso, representando um agregado de experiências individuais e ligações emocionais ao espaço, isto é, espaço enquanto lugar de afectos; urbanização refere-se à cidade enquanto instrumento abstracto do capitalismo, cidades enquanto "os centros vitais do modo de produção", consequentemente lugares objectivos com um valor de troca, isto é, espaço enquanto mercadoria'. Desta forma, o espaço urbano, e sobretudo "a produção de espaço urbano" gera tensões entre aqueles que pretendem maximizar o valor de troca e os que procuram maximizar, ou por vezes apenas manter, determinados valores de uso. A contradição entre urbanismo e urbanização expõe assim o conflito entre a experiência de viver na cidade contemporânea e a forma como o ambiente urbano é fisicamente determinado pelos processos de acumulação do capitalismo pós-industrial, ou pós-fordista.

0 presente ensaio propõe uma análise das dinâmicas de urbanização emergentes das transformações estruturais do capitalismo pós-fordista. Examinam-se alguns dos aspectos formais da organização do espaço urbano; como o cânon modernista modificou aspectos elementares da sua morfologia; e como - no seio de uma cultura "pós-moderna" de desenho urbano, orientada por um entendimento do espaço enquanto mercadoria uma reacção com vista a restaurar certos princípios elementares de composição espacial, está presentemente a tomar forma. Procurar-se-á demonstrar que, em resposta a forças de mercado que tendem a produzir cidades incoerentes e fragmentadas, é possível identificar um conjunto de princípios integradores de desenho urbano com vista a resolver a oposição que Merrifield estabelece entre urbanismo e urbanização. Demonstrar-se-á ain-

\footnotetext{
* Arquitecto-Urbanista, Mestre em Planeamento Urbano, Doutorando em Planeamento Urbano e Políticas de Desenvolvimento na Rutgers University, NJ. Contacte: lbalula@icopper.net

A distinção entre o valor de uso e o valor de troca do espaço urbano, tal como estabelecida por Logan, J. e Harvey, M. (1987), baseia-se na elaboração de David Harvey a partir des conceites originais de K. Marx.
} 


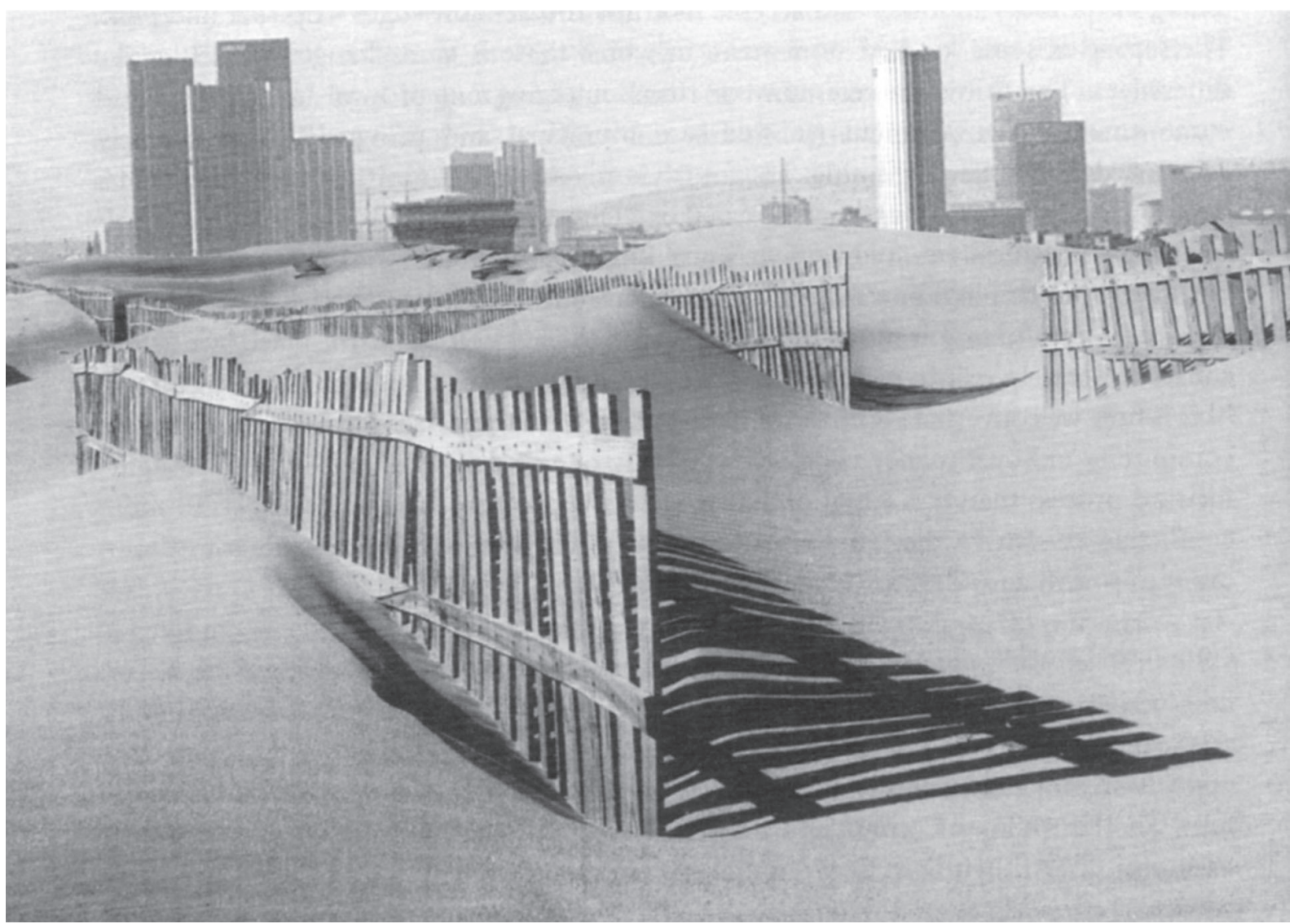

Fotomontagem: Peter Lyssiotis

da a importância do espaço público no reforço dos processos comunicativos da esfera pública²; e que, perante a crescente "despacialização" desta esfera pública, os planeadores com responsabilidades no desenho da cidade têm hoje a oportunidade de recuperar os princípios de organização espacial, "esquecidos" pelo modernismo, que contribuem para reforçar a comunicação humana e a coesão social.

\section{Interpretação e produção do espaço urbano}

Ninguém questiona que o espaço urbano, enquanto produto da acção humana, seja historicamente produzido e socialmente interpretado. A sua transformação está intimamente ligada à evolução histórica e a sua morfologia é produto de determinados regimes de acumulação económica e correspondentes modos de regulação social. O que no entanto é questionável, perante a fragmentação da sociedade urbana contemporânea, é o entendimento do espaço urbano enquanto a expressão fixa de uma cultura uniforme. É certo que a forma urbana tende a "exprimir e realizar os interesses da classe dominante, de acordo com um determinado modo de produção e um modo específico de regulação" (Castells, 2003:59). No entanto, visto que diferentes indivíduos ou grupos atribuem diferentes valores ao espaço, o processo de urbanização torna-se um fenómeno social complexo, e polarizador de tensões e conflitos. Objectivos divergentes levam grupos de interesse a mobilizar-se para estimular, ou para limitar, o desenvolvimento urbano. Enquanto que coligações pró-desenvolvimento, ou "growthmachines" (Molotch, 1976:309), formadas por grupos de interesse económico associados a grupos político-governamentais promovem projectos imobiliários com o duplo objectivo de maximização do lucro privado e dos pressupostos benefícios so-

\footnotetext{
2 A noção de "esfera pública", tal como definida por Habermas: uma arena de deliberação política que transcende as organizações políticas formais (parlamento, partidos, etc.) ao incluir igualmente os círculos deliberativos, mais ou menos informais, da sociedade civil.
} 
ciais e económicos decorrentes, algumas organizações da sociedade civil, motivadas por interesses ambientais, de preservação histórica, ou de equidade social, têm vindo a organizar-se para contestar esses mesmos projectos. Da mesma forma, noções de "bairro" e "comunidade" têm vindo a tornar-se relevantes nos processos de contestação dos usos do espaço urbano. Como Paul Clark bem sintetiza, "a produção de espaço tem vindo a ser permeada por uma crescente sensibilidade em relação aos lugares" (Clark, 2003:35).

Neste sentido, é útil observar como as alterações estruturais decorrentes dos processos de globalização têm igualmente produzido importantes efeitos na definição do espaço urbano. Ao longo das últimas três décadas temos assistido a profundas transformações sociais e económicas, a saber, resumidamente: a crescente transferência de emprego do sector industrial para o sector de serviços; o crescimento florescente de novas tecnologias de comunicação e de transferência instantânea de informação; o domínio dos grandes grupos económicos e a internacionalização dos seus investimentos; a entrada das mulheres no mercado de trabalho e consequentes alterações na estrutura do agregado familiar; o acentuado recuo do Estado-providência e o enfraquecimento do movimento sindical; a crescente privatização dos bens e actividades tradicionais do Estado; a competição inter e intra-urbana pela acumulação de capital fixo em projectos imobiliários; a emergência de parcerias entre os sectores público e privado em actividades de desenvolvimento urbano; e a articulação de novos valores liminais e ecológicos por parte da classe média. Todas estas alterações estruturais, por sua vez, "estão a ser reproduzidas no espaço através de relações de propriedade articuladas pelo sector imobiliário, mediadas pelas profissões implicadas no desenho urbano, e reflectidas no (bem como condicionadas pelo) ambiente construído" (Knox, 2003:357). Será portanto razoável sugerir que o planeamento e o desenho urbano - que durante o período modernista terão sido instrumentais para o desenvolvimento do capitalismo industrial - prosseguem hoje uma lógica espacial inerente ao capitalismo pós-industrial.

O modelo de urbanização modernista é frequentemente acusado de ter contribuído para o declínio da cidade tradicional e da sua inerente cultura urbana. O desenvolvimento urbano moder- nista, fundado nos mesmos princípios de racionalismo positivista que determinaram o progresso tecnológico industrial, constituiu uma espécie de "experimentação social" baseada em formas arquitectónicas totalmente novas e na rejeição de todo o conhecimento acumulado acerca das formas de "fazer cidade" do passado. O planeamento urbano modernista promoveu áreas urbanas hiper-simplificadas, rigidamente separadas por critérios de exclusividade funcional, eixos urbanos sem outra função que a da circulação de veículos entre essas zonas funcionais, e, em geral, sistemas urbanos completamente organizados em função de uma "inevitável" dependência do automóvel e consequente congestão urbana, seguida pela construção de auto-estradas e expansão suburbana, seguida por mais congestão e construção de mais auto-estradas (Newman e Kenworthy, 2003:241). Assim tomaram forma as megacidades, ou áreas metropolitanas, que constituem hoje o suporte espacial do investimento económico e das relações sociais. Sendo certo que "os padrões de povoamento constituem a fundação física da nossa sociedade" (Calthorpe, 1993:16), tal como na sociedade, também neles ocorrem profundas fracturas. Os sistemas metropolitanos contemporâneos constituem "constelações descontínuas de fragmentos espaciais, peças funcionais, e fracturas sociais" (Castells, 2003:59) - e são precisamente estas condições que definem já o contexto de um urbanismo pós-moderno.

\section{Organizações formais e funções sociais do espaço público}

Uma outra questão central à dialética entre urbanismo e urbanização estrutura-se através da definição de - e nas relações entre - espaço público e espaço privado. Os espaços públicos, enquanto infra-estruturas físicas da vida social, tiveram desde sempre uma importância fundamental para a cidade: é neles que as pessoas se encontram e desenvolvem actividades diversas, económicas, políticas e culturais. Os espaços públicos podem servir diferentes usos e possuir diferentes formas, mas na sua maioria são tradicionalmente constituídos por ruas, praças, parques. Uma concepção pré-modernista do espaço público, como a de Camillo Sitte no final do século dezanove, salientava o seu carácter "contido" enquanto essencial: os espaços 


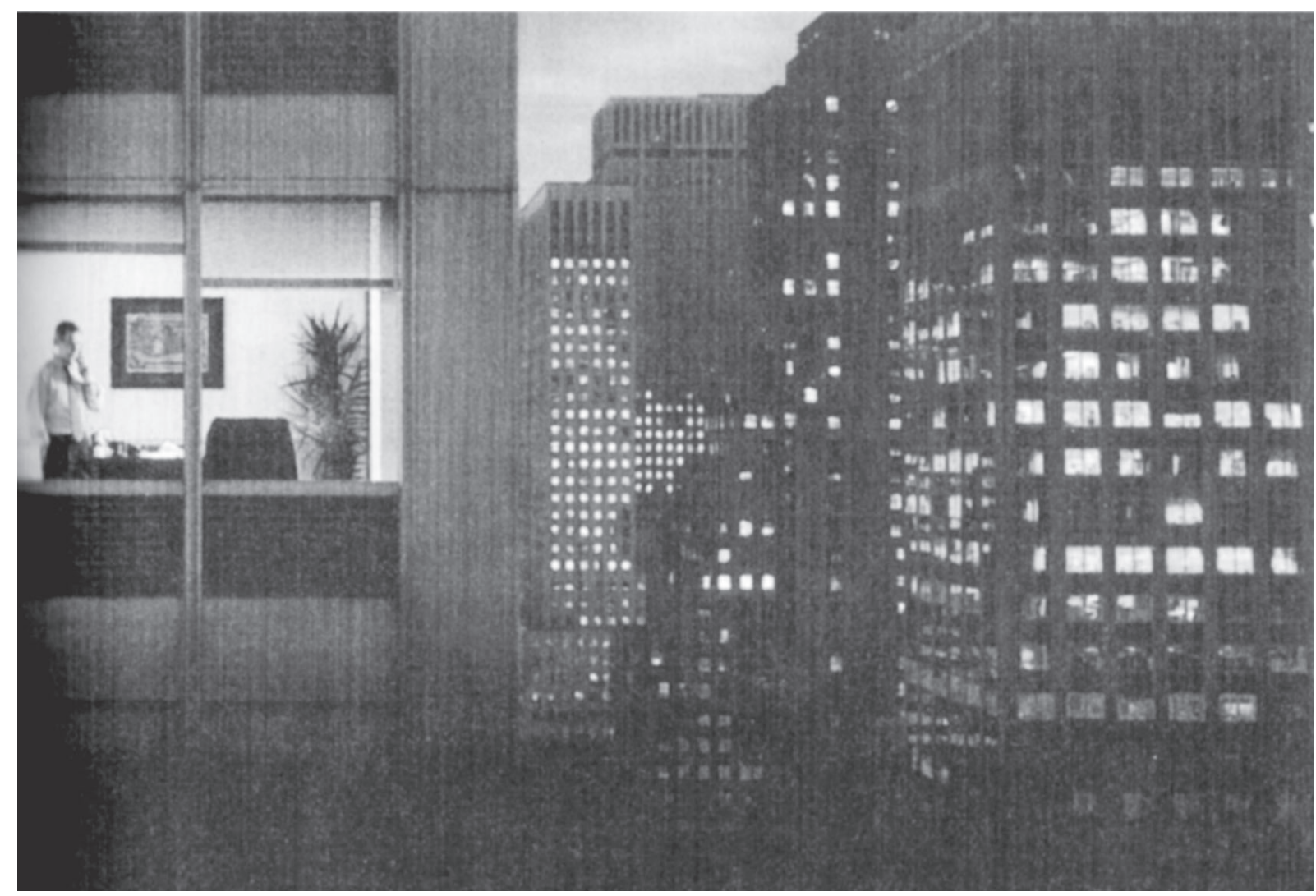

Fotomontagem: Peter Lyssiotis

públicos, enquanto "salas de estar" da cidade, deveriam ser visualmente fechados a partir de qualquer ponto do seu interior (Sitte, 1889). Raymond Unwin, seguidor das ideias de Sitte e figura central do movimento das cidades-novas inglesas, descreveu exaustivamente as regras de desenho que deveriam regular as relações entre o espaço público e os edifícios privados circundantes, por forma a obter uma desejável sensação espacial de contenção e término de vistas (Unwin, 1909).

O movimento moderno, no entanto - dominante na arquitectura e urbanismo a partir da segunda metade do século vinte - opôs-se frontalmente a este entendimento do espaço público. Ao advogar vastos espaços abertos, propícios à implantação livre e flexível de edifícios isolados, o desenho urbano modernista condenou irremediavelmente a relação íntima entre o espaço público e os edifícios que o circundam. A pouca atenção que os planeadores do modernismo terão prestado aos espaços públicos da cidade tradicional, terá sido para neles intervir através de projectos de "renovação" urbana e impor a simplicidade dos traçados geo- métricos a relações espaciais previamente complexas e orgânicas. Um dos resultado mais negativos do desinteresse pelos espaços públicos tradicionais, associado à ideologia do zonamento funcional, foi a produção de inúmeros espaços vazios ou subutilizados uma parte do tempo, com pouca ou nenhuma relação com outros espaços urbanos, e o consequente reforço da fragmentação espacial e social.

Contra o anti-historicismo do Movimento Moderno, uma aproximação neo-tradicional ao desenho urbano começou a definir-se na década de 60 e tem vindo a ganhar uma crescente influência nos processos de definição formal do espaço urbano. Gordon Cullen desenvolveu a ideia de visão serial de Sitte, dissecando em detalhe a forma como o espaço urbano é percepcionado à medida que é percorrido (Cullen, 1986). Kevin Lynch, igualmente interessado na forma como a cidade é percebida pelos seus habitantes, desenvolveu a célebre teoria da "imageabilidade", ou seja, a identificação dos elementos da estrutura urbana que devem estar presentes para criar uma imagem, e uma sensa- 
ção intensa, de coerência espacial (Lynch, 1960). Jane Jacobs lançou um verdadeiro assalto às fundações do planeamento urbano modernista, nomeadamente aos princípios do $\mathrm{CIAM}^{3}$, com uma eloquente descrição do sucesso social e económico dos padrões urbanos tradicionais rejeitados pelo modernismo (Jacobs, 1965). Arquitectos como Leon Krier e Rob Krier assinalaram a importância da complexidade tipológica dos tecidos urbanos e reinstauraram a importância dos espaços públicos "contidos", definidos por edifícios: “os edifícios devem constituir a carne da cidade e a pele do espaço público" (Krier, 1978). Ruas e praças voltaram a fazer parte dum alfabeto, através do qual é possível ler e desenhar o espaço urbano (Krier, 1979). Tornou-se sobretudo essencial criar de novo "espaço urbano positivo", quer dizer, espaço urbano definido por edifícios, em vez de espaço intersticial, ou aquilo que sobra depois da implantação dos edifícios (Alexander, 1987). Também no actual panorama do planeamento urbano norte-americano a crescente influência de movimentos como o "Novo Urbanismo", o "Smart Growth", ou o "Transport Oriented Development (TOD)" atesta uma clara aproximação a modelos neo-tradicionais de povoamento e de desenho urbano. Na verdade, o que todos estes movimentos e autores procuram introduzir na agenda do planeamento é a necessidade de voltar a desenhar o meio urbano de acordo com as regras e os elementos formais da cidade tradicional.

A importância funcional do espaço público tem vindo igualmente a sofrer consideráveis transformações ao longo das últimas décadas. Como afirma Madanipour, "comparativamente à maioria dos períodos históricos do passado, a importância do espaço público é hoje bastante reduzida" (Madanipour, 2003:142). Isto é, em parte, resultado da descentralização e dispersão territorial das cidades, mas também é resultado de uma crescente "despacialização" da esfera pública. A dimensão crescente da cidade (estimulada pelas tecnologias de transporte), a especialização das actividades, a separação entre os lugares de residência e de trabalho, e as novas tecnologias de comunicação, têm vindo a desconstruir a coerência simbólica e funcional do espaço público urba- no - a tradicional infra-estrutura espacial da esfera pública. Quando pessoas e actividades se distribuem no espaço em padrões cada vez mais dispersos, o espaço público perde parte das funções que outrora cumpriu na vida social da cidade: lugar de encontro para o debate político, para trocas comerciais, e para representações culturais. Da mesma forma, quando as redes de comunicação instantânea criam novas arenas de debate e sistemas de troca que não dependem do espaço físico nem de contactos face-a-face, a importância dos espaços urbanos vê-se gradualmente diminuida. O papel coesivo do espaço público, entendido enquanto "o lugar colectivo onde as pessoas desenvolvem as actividades funcionais e rituais que estruturam a comunidade" (Carr et al., 1992:xi) entrou em processo de rápida erosão e, consequentemente, os espaços públicos estão em vias de tornar-se irrelevantes para os processos comunicativos de uma esfera pública cada vez mais "despacializada".

Acrescidamente, numa altura em que as autoridades públicas municipais não têm a capacidade, ou a vontade, de o fazer, são os promotores privados que têm vindo a assumir a implementação e a gestão dos espaços públicos. Uma das consequências visíveis do investimento privado em espaços públicos é a implementação generalizada de espaços (semi-)públicos "seguros" e "atractivos" fortemente orientados para o consumo comercial e/ou turístico de massas. Uma forte ênfase na imagem (cidade enquanto mercadoria espectacular) e na segurança (cidade enquanto ambiente social controlado) é entendida enquanto o meio mais eficaz para a promoção das localidades, e para atrair e reter o investimento económico. Centros comerciais, onde o espaço - exclusivamente orientado para o consumo - é constantemente vigiado por forma a eliminar comportamentos indesejáveis; condomínios residenciais murados, onde "o público" é submetido a uma pré-selecção; "parques temáticos", onde a experiência urbana é completamente determinada pela indústria do divertimento; ou jardins e praças que são fechados a determinadas horas para excluir usos "impróprios", entre outros exemplos, são lugares em que faltam muitas das qualidades que definem os verdadeiros espa-

\footnotetext{
${ }^{3}$ Congrés Internationaux d'Architecture Moderne, que se reuniu pela primeira vez em 1928 e veio a aprovar a Carta de Atenas em 1933.
} 
ços públicos de encontro e interacção social. Em resumo, a crescente produção e gestão do espaço urbano pelo sector privado tem vindo a limitar drasticamente a sua dimensão verdadeiramente "pública".

O corrente envolvimento do sector privado no desenvolvimento e gestão da cidade, no entanto, não deve ser ponderado apenas nos seus aspectos negativos. $\mathrm{O}$ trabalho colaborativo dos planeadores físicos da cidade com a administração pública, com grupos de interesse da sociedade civil, mas também com os grandes investidores privados - a versão mais "liberal" de um regime de governância pode ser orientado por forma a encorajar espaços que promovam uma relação equilibrada entre os interesses privados e as funções cívicas necessárias a um público diversificado. Interessa salientar que a tarefa de um planeador físico é distinta da tarefa do arquitecto (trabalhando num único imóvel) pois o seu projecto transcende linhas de propriedade e opera através de divisões entre o público e o privado. Numa altura em que "os mercados imobiliários subdividem o ambiente urbano em compartimentos estanques, gerando cidades incoerentes e fragmentadas", um bom desenho urbano deverá procurar "contrariar este factor económico através do reforço da coesividade da experiência urbana" (Sternberg, 2000:275). Assim sendo, o esforço colaborativo entre planeadores, investidores privados e o Estado deverá procurar contrariar a fragmentação socioespacial, e encorajar a tolerância relativamente a um público cada vez mais diversificado e potencialmente conflitual. Como Madanipour afirma, "a criação de "nós inclusivos' pode constituir um passo positivo para a redução dos potenciais conflitos provenientes de diferentes interpretações e expectativas acerca do espaço urbano, e promover um urbanismo de tolerância e coesão social" (Madanipour, 2003:149).

\section{Inovação e tradição: as opções do desenho urbano}

De um ponto de vista puramente estético, ou estilístico, "um urbanismo de tolerância e coesão social" pode assumir diversas formas. No entanto, é importante notar que a produção estética se encontra igualmente integrada num regime de mercadoria. O modernismo promoveu o "design" enquanto mercadoria cultural, e o planeamento urbano pós-moderno pode ser visto enquanto um prolongamento espacial dessa tendência. Numa era em que as cidades apostam fortemente na imagem para ganhar vantagens competitivas relativamente a outras cidades, a produção e o consumo de arquitectura e espaço público encontram-se sujeitos às mesmas condições de mercado que qualquer outro produto de consumo. $\mathrm{O}$ "edifício assinado" pelo arquitecto superstar é exemplar de um tipo de produção pós-moderna de espaço urbano que combina marketing de imagem, branding, e estímulo

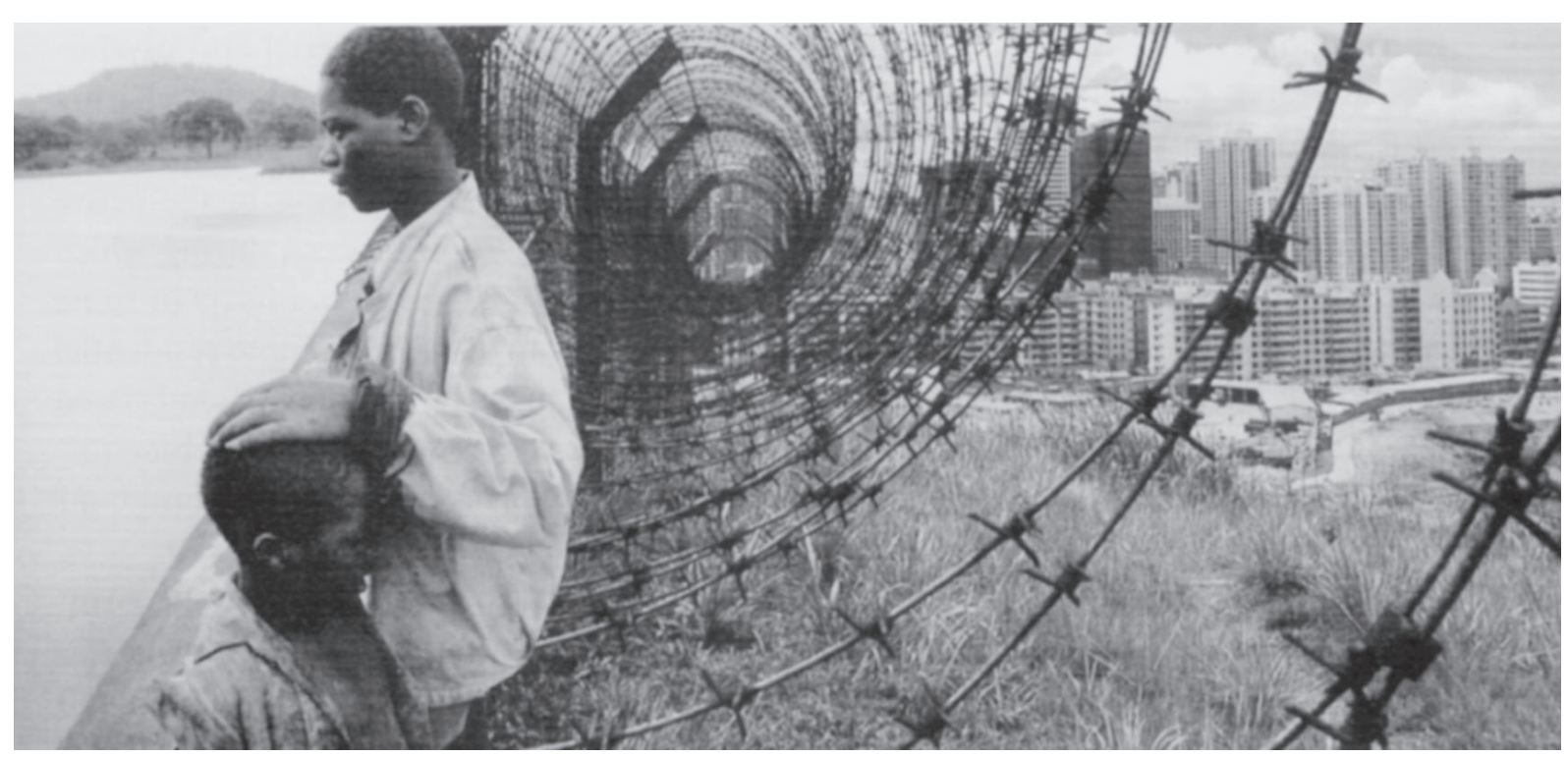

Fotomontagem: Peter Lyssiotis 
ao consumo de produtos "de marca". E, neste contexto, a ideia de "novidade" é fundamental. A propósito da lógica cultural do capitalismo pós-industrial, Jameson assinala a necessidade económica de produzir ambientes com uma "aparência de novidade" a um ritmo cada vez mais "frenético" (Jameson, 1984:56). Afinal, é esta a ideologia subjacente à produção espacial pós-moderna, já latente, aliás, no ideário do espaço urbano modernista: “inovação estética e experimentação, com vista à captação e acumulação de capital" (Clarke, 2003:37).

Inovação estética e "aparência de novidade" são conhecidas estratégias utilizadas no marketing da maioria dos produtos de consumo: de acordo com uma lógica estritamente economicista, é suposto que os consumidores substituam bens (antigos e "desactualizados") por outros bens relativamente idênticos (mas "actualizados") com uma frequência cada vez mais curta, com vista a aumentar os lucros da produção e acelerar a renovação dos stocks. Quando aplicada ao espaço urbano, no entanto, a "aparência de novidade" revela-se uma tendência estética bastante problemática. Ainda que tal estratégia, de um ponto de vista estritamente económico, possa até resultar - implicando lucros imobiliários com a substituição de estruturas urbanas, digamos, cada vinte anos - o entendimento do espaço urbano enquanto mais uma mercadoria substituível e "actualizável" é socialmente insustentável. A relação humana com o espaço baseia-se num sentido de permanência, não de transitoriedade; e não se trata apenas de uma questão histórica, cultural, ou social, mas igualmente de uma condição física, emocional e orgânica. Ambientes urbanos saudáveis sobrevivem inúmeras gerações, e as pessoas desenvolvem afectos com os lugares construídos ao longo de toda a sua vida. No entanto "a paisagem pós-moderna representa uma destruição de longevidade, de acumulação cultural e de supostas garantias de permanência (...) resultante da oposição entre os interesses de mercado e o espírito do lugar" (Zukin, 2003:52), em que este é sistematicamente sacrificado em função daqueles. Neste sentido, o desenho do espaço público deve procurar apostar na continuidade histórica de acordo com uma lógica de acumulação cultural, e não apenas seguir uma estética "da moda", tipicamente orientada para os imperativos da concentração de capital económico, em detrimento do capital social e do capital cultural.

Novas áreas urbanas, novos espaços públicos, e intervenções em áreas urbanas e espaços públicos existentes, devem contribuir formalmente para reforçar o sentido de permanência e de estabilidade e não reflectir apenas as tendências passageiras de uma sociedade de consumo impaciente por novidades e ansiosa por mudança. Cabe aos planeadores urbanos com responsabilidades no desenho da cidade investigar os bons exemplos de organização espacial pré-modernista, por forma a redescobrir as qualidades do "espaço urbano positivo" (Alexander et al., 1977), isto é, espaço público "contido" no qual as pessoas se possam encontrar para actividades variadas, e não apenas com os desígnios reducionistas do consumo ou divertimento de massas. Alguns teóricos da cidade consideram os argumentos a favor dos usos do desenho urbano para influenciar o comportamento social enquanto puro determinismo ambiental. No entanto, "é tão simplista afirmar que a forma física da comunidade não tem qualquer impacto no comportamento humano, como afirmar que é possível promover determinados comportamentos através do desenho urbano" (Calthorpe, 1993:9). O desenho, por si só, não será concerteza suficiente para provocar mudança social, mas comprovadamente a forma física dos lugares inibe determinadas actividades enquanto favorece certas outras. Os princípios de composição espacial que produziram as ruas e as praças pré-modernistas - espaços que ainda hoje continuamos a gostar e a querer preservar - podem provar-se decisivos para a recuperação das qualidades perdidas dos espaços públicos. Novos modelos de fazer cidade deverão pois "procurar restaurar o melhor das antigas tradições do desenho urbano, adaptando-as às novas condições" (Calthorpe, 1993:9), tendo em vista a promoção de lugares urbanos capazes de incentivar a coesão social e estimular os processos comunicativos da esfera pública. 


\section{Bibliografia:}

ALEXANDER, C. et al. (1987), A New Theory of Urban Design, New York, Oxford University Press.

ALEXANDER, C. et al. (1977), A Pattern Language, New York, Oxford University Press.

CALTHORPE, P. (1993), The Next American Metropolis. Ecology, Community, and the American Dream, New York, Princeton Architectural Press.

CARR, S. et al. (1992), Public Space, Cambridge, Cambridge University Press.

CASTELLS, M. (2003), "The new historical relationship between space and society" in CUTHBERT, A. (ed.) Designing Cities: Critical Readings in Urban Design, Oxford, Blackwell.

CLARKE, P. W. (2003), "The economic currency of architectural aesthetics" in CUTHBERT, A. (ed.) Designing Cities: Critical Readings in Urban Design, Oxford, Blackwell.

CUlLEN, G. (1986), The Concise Townscape, London, Architectural Press.

FAINSTEIN, S. (2001), The City Builders: Property Development in New York and London, 1980-2000, University Press of Kansas.

JACOBS, J. (1965), The Death and Life of Great American Cities, Harmondsworth, Penguim.

JAMESON, F. (1984), "Postmodernism, or the cultural logic of late capitalism", New Left Review, July/August.

KNOX, P. L. (2003), "The design professions and the built environment in a postmodern epoch" in CUTHBERT, A. (ed.) Designing Cities: Critical Readings in Urban Design, Oxford, Blackwell.

KRIER, L. (1978), Rational Architecture, Brussels, Archives d'Architecture Moderne.

KRIER, L. (1979), Urban Space, London, Academy Editions.
LOGAN, J. e MOLOTCH, H. (1987), Urban Fortunes: The Political Economy of Place, Berkeley, University of California Press.

LYNCH, K. (1960) The Image of the City, Cambridge, MIT Press.

MADANIPOUR, A. (2003), "Why are the design and development of public spaces significant for cities?" in CUTHBERT, A. (ed.) Designing Cities: Critical Readings in Urban Design, Oxford, Blackwell.

MERRIFIELD, A. (2002), Dialectical Urbanism: Social Struggles in the Capitalist City, New York, Monthly Review Press.

MOLOTCH, H. (1976), "The City as a Growth Machine", American Journal of Sociology 82(2).

MOSSBERGER, K. E STOKER G. (2001), "The Evolution of Urban Regime Theory: The Challenge of Conceptualization", Urban Affairs Review 36(6).

NEWMAN, P. e JOHN K. (2003), “Sustainability and cities: summary and conclusions" in CUTHBERT, A. (ed.) Designing Cities: Critical Readings in Urban Design, Oxford, Blackwell.

SITTE, C. (1889) The Art of Building Cities.

STERNBERG, E. (2000), "An integrative theory of urban design", Journal of the American Planning Association, 66(3).

STONE, C. (1993), "Urban Regimes and the Capacity to Govern: A Political Economy Approach", Journal of Urban Affairs, 15.

UNWIN, R. (1909), Town Planning in Practice: An Introduction to the Art of Designing Cities and Suburbs, New York, B. Blom.

ZUKIN, S. (2003), "The postmodern debate over urban form" in CUTHBERT, A. (ed.) Designing Cities: Critical Readings in Urban Design, Oxford, Blackwell. 